ORIGINAL ARTICLE

\title{
Antimicrobial susceptibility of Neisseria gonorrhoeae strains isolated in Guangzhou, China, 1996-2001
}

\author{
H P Zheng, W L Cao, X Z Wu, L G Yang
}

Sex Transm Infect 2003;79:399-402

See end of article for authors' affiliations ......................

Correspondence to: He-ping Zheng, Guangdong Provincial Centers for Skin Diseases and STIs Control and Prevention, 10, Xian Lie Dong Heng Road, Guangzhou, 510500, P R China; zhfengzh2000@ yahoo.com.hk

Accepted for publication 14 April 2003

\begin{abstract}
Objective: To investigate the in vitro antimicrobial susceptibility and resistant trends of Neisseria gonorrhoeae strains isolated in Guangzhou, from 1996 to 2001.

Methods: The agar dilution method was used to determine the minimum inhibitory concentrations (MICs) to four antimicrobials, penicillin G, ciprofloxacin, ceftriaxone, and spectinomycin. The resistance of all strains to four antibiotics was interpreted according to criteria used in the project of surveillance of gonococcal antibiotic susceptibility in the WHO Western Pacific Region. Penicillinase producing $N$ gonorrhoeae (PPNG) was analysed by the paper acidometric method.

Results: 793 consecutive N gonorrhoeae isolates collected in Guangzhou were studied from 1996 to 2001. A total of 55 strains of PPNG were identified and the prevalence rapidly spread from $2 \%$ to $21.8 \%$. Of the four antibiotics examined, ceftriaxone and spectinomycin appeared to be the most effective agents although two spectinomycin resistant strains were isolated in 1996. Their $\mathrm{MIC}_{50}, \mathrm{MIC}_{90}$, and geometric mean MIC (MICmean) were all between the sensitive ranges of the interpretative criteria and remained stable over the years. However, resistance increased continuously to penicillin $G$ and dramatically to ciprofloxacin. In 1996-2001, MIC $50, M_{90}$, and MICmean of penicillin $\mathrm{G}$ increased from $1 \mu \mathrm{g} / \mathrm{ml}$ to $2 \mu \mathrm{g} / \mathrm{ml}, 4 \mu \mathrm{g} / \mathrm{ml}$ to $32 \mu \mathrm{g} / \mathrm{ml}$, and $0.68 \mu \mathrm{g} / \mathrm{ml}$ to $2.35 \mu \mathrm{g} / \mathrm{ml}$, respectively; those of ciprofloxacin steeply increased from $0.12 \mu \mathrm{g} / \mathrm{ml}$ to $4 \mu \mathrm{g} / \mathrm{ml}, 2 \mu \mathrm{g} / \mathrm{ml}$ to $32 \mu \mathrm{g} / \mathrm{ml}$, and $0.14 \mu \mathrm{g} / \mathrm{ml}$ to $2.62 \mu \mathrm{g} / \mathrm{ml}$ in 1996-9, respectively, and then declined slightly in 2000-1. The prevalence of resistant isolates spread from $57.2 \%$ to $81.8 \%$ for penicillin $G$ and from $17.6 \%$ to $72.7 \%$ for ciprofloxacin over the 6 years.

Conclusion: Resistance to penicillin and ciprofloxacin increased greatly during 1996-2001. Ceftriaxone and spectinomycin should be used as the first line agents in treating gonorrhoea. It is of great importance to continuously survey the susceptibilities of $N$ gonorrhoeae to antibiotics in controlling the spread of gonococcal infections.
\end{abstract}

$\mathrm{N}$ eisseria gonorrhoeae infections represent one of the most widely disseminated sexually transmitted diseases in China. A total of 837400 cases of gonorrhoea were reported in 1999, which accounted for $40.7 \%$ of all STDs and increased by $32.3 \%$ over $1998,{ }^{1}$ Guangdong, located in the far south of China, was one of the provinces with the highest prevalence. During 1996-2000, 131738 cases were reported, with epidemiological links to Hong Kong and other south east Asian countries because of increasing travel to and from those destinations. ${ }^{2}$

The national guideline for therapy in 1993 recommends one of the following single doses regimens as first line therapy for uncomplicated gonorrhoea: ciprofloxacin $500 \mathrm{mg}$ or ofloxacin $400-600 \mathrm{mg}$ orally, ceftriaxone $250 \mathrm{mg}$ or spectinomycin $2 \mathrm{~g}$ intramuscularly. Penicillin is only recommended if resistance is known to be rare and tetracycline is chosen if the patients are allergic to these antibiotics. With the emergence and spread of resistant strains, penicillin and tetracycline are no longer listed as first line agents for treatment of gonorrhoea in the new guideline since August 2000.

Prompt and appropriate antimicrobial treatment is important in eliminating the pathogen and limiting its transmission. However, the antibiotic resistance of Neisseria gonorrhoeae is constantly changing as a result of the extensive use and/or abuse of antibiotics for treatment of gonorrhoea and importation of resistant strains. An early survey showed that the rate of penicillin resistant strains increased from $47.8 \%$ in 1987 to $64.5 \%$ in 1992 in China. ${ }^{3}$ Recently, the strains with high level resistance to quinolones were found in Guangzhou. ${ }^{4}$ Therefore, the need for epidemiological study of this organism and surveillance of its susceptibility to common antibiotics is reinforced. A project on the surveillance of gonococcal antibiotic susceptibility in the WHO Western Pacific Region has been carried out in China. As one of the members of the research group, we annually determine the in vitro susceptibility of $N$ gonorrhoeae isolates in Guangzhou, the capital city of Guangdong province. This paper analysed the prevalence of penicillinase producing $N$ gonorrhoeae (PPNG), the antimicrobial susceptibilities, and resistant trends of $N$ gonorrhoeae isolated in Guangzhou from 1996 to 2001.

\section{METHODS}

\section{Bacterial isolates}

In all, 793 consecutive isolates of $N$ gonorrhoeae were collected from outpatients with gonorrhoea attending STD clinics of Guangdong Provincial Centers for STIs and Skin Diseases Control and Prevention, and Guangzhou Center for STD Control and Prevention from 1996 to 2001 in Guangzhou, China.

\section{Isolation of $\mathrm{N}$ gonorrhoeae}

Urethral and endocervical specimens were directly inoculated on Thayer-Martin medium (GC agar base + haemoglobin + growth supplement + VCNT) and GC agar supplemented with $10 \%$ defibrinated sheep blood. The plates were incubated at $35^{\circ} \mathrm{C}$ in a humid candle extinction jar for $36-48$ hours. The isolates were identified as $N$ gonorrhoeae on the basis of colony morphology, Gram staining, oxidase test, and carbohydrate 
Table 1 Interpretation of susceptibility $(\mu \mathrm{g} / \mathrm{ml})$

\begin{tabular}{llll}
\hline Antibiotic & Sensitive & Intermediate & Resistant \\
\hline Penicillin & 0.03 & $0.06-0.5$ & $\geqslant 1$ \\
Spectinomycin & $\leqslant 32$ & - & $\geqslant 64$ \\
Ceftriaxone & $\leqslant 0.03$ & $0.06-0.5$ & $\geqslant 1$ \\
Ciprofloxacin & $\leqslant 0.03$ & $0.06-0.5$ & $\geqslant 1$ \\
\hline
\end{tabular}

degradation tests. All stains were preserved in skimmed milk and stored at $-70^{\circ} \mathrm{C}$ before use.

\section{Antibiotic susceptibility}

All the isolates were examined for susceptibility to penicillin G, ciprofloxacin, ceftriaxone, and spectinomycin by the agar plate dilution method for minimum inhibitory concentrations (MICs). ${ }^{5}$ The ranges of concentration of antibiotics were as follows: penicillin $\mathrm{G}, 0.3 \mathrm{l}-32 \mu \mathrm{g} / \mathrm{ml}$; tetracycline, $0.5-32 \mu \mathrm{g} / \mathrm{ml}$; spectinomycin, $4-128 \mu \mathrm{g} / \mathrm{ml}$; ciprofloxacin, $0.15-32 \mu \mathrm{g} / \mathrm{ml}$ and ceftriaxone, $0.002-1 \mu \mathrm{g} / \mathrm{ml}$. The sensitivity of isolates was determined according to agar plate dilution methods similar to those in use by the Western Pacific WHO GASP programme as follows. The medium used was GC agar (Oxoid) supplemented with 10\% defibrinated sheep blood. Pure subculture from 18 to 24 hours' growth on GC agar was suspended in saline and adjusted to contain approximately $10^{8} \mathrm{cfu} / \mathrm{ml}$ as inoculum. A multipoint inoculator was used to inoculate the suspension onto antibiotic containing media. After overnight incubation at $35^{\circ} \mathrm{C}$ in a carbon dioxide incubator, the MICs were read.

\section{Interpretation of susceptibility}

Two methods were used in AHPWPR, one is the American method and other the non-American method. We apply the latter method, modified by using sheep blood instead of lysed horse blood. The laboratory obtained satisfactory results in the China GASP QA programme external quality assurance programme conducted by the Nanjing National Reference STD centre. The American method uses MIC $\geqslant 2 \mathrm{mg} / \mathrm{l}$ as penicillin resistance, while the non-American method standard is $1 \mathrm{mg} / \mathrm{l}$. The criteria for resistance in this test system are shown in table 1.

WHO $N$ gonorrhoeae reference strains A-E, kindly provided by Dr Ye Shunzhang, the National Center for STD control, Nanjing, were used as controls in each antimicrobial assay. Because these reference strains are all quinolone sensitive, we also reference the external QA results as control.

A $\beta$ lactamase assay was performed by the paper acidometric method. ${ }^{6}$ WHO reference strains A and E were used as negative and positive control, respectively.

\section{Statistics}

Geometric MICs were determined using the base $e_{2}$ logarithms. The Mann-Whitney U test was used for evaluating the trends of the resistant rates.

\section{RESULTS}

Among the 793 gonococcal isolates examined, 55 PPNG strains were identified by the paper acidometric method. The prevalence dramatically increased from $2 \%$ to $21.8 \%$ in $1996-$ $2001(\mathrm{U}=6.38, \mathrm{p}<0.01)$ (table 2 ).

The distribution of $\mathrm{MIC}_{50}, \mathrm{MIC}_{90}$, and MICmean of the four antibiotics to 793 consecutive strains collected in Guangzhou during these 6 years is summarised in table 3. Out of the four antibiotics tested, ceftriaxone and spectinomycin appeared to be the most effective agents and the MICs remained stable over the years, while MICs of penicillin G and ciprofloxacin enlarged dramatically. $\mathrm{MIC}_{50}, \mathrm{MIC}_{90}$, and MICmean of penicillin G multiplied by 2, 8, and 3.5 times from 1996 to 2001, respectively; those of ciprofloxacin by 33, 16, and 18.7 times higher in 1996-9, respectively, and declined slightly in 2000-1.

Antimicrobial susceptibilities of 793 strains, interpreted according to WHO standards, were shown in table 2 . It appeared that the strains were more sensitive to ceftriaxone and spectinomycin. Only two spectinomycin resistant gonococcal strains were isolates during the 6 years. The proportion of sensitive strains to penicillin decreased from $8.4 \%$ to $0.9 \%$, while the resistant rate increased from $57.2 \%$ to $81.8 \%$ $(\mathrm{U}=4.39, \mathrm{p}<0.01)$. A significant trend for increasing resistance to ciprofloxacin developed dramatically from 1996 to 2001. The proportion of sensitive organisms dropped from $18.6 \%$ to $1.8 \%$, while the resistant rate rose steeply from $17.6 \%$ to $72.7 \%(U=9.67, p<0.01)$.

\section{DISCUSSION}

The antibiotic resistant profile changes constantly over time. Since the emergence of PPNG in 1976 and the chromosomally mediated penicillin resistant isolate in 1983, the resistant gonococci have spread worldwide and the prevalence increased rapidly. In south east Asian, very high proportions of penicillin resistance were recorded-Korea $(91 \%)$, the Philippines (89\%), China $(80 \%)$, Singapore $(58 \%)$, Hong Kong (54\%), and Vietnam (48\%) in 2000..$^{7}$ We identified 546 penicillin resistant strains out of 793 consecutive isolates in Guangzhou, in which 55 were PPNG and 491 chromosomally mediated penicillin resistant. The prevalence of PPNG were lower during the first 4 years but rose steeply from $5.4 \%$ to $21.8 \%(\mathrm{U}=4.2, \mathrm{p}<0.01)$ in the past 2 years, indicating that Guangzhou had become a highly prevalent region. The penicillin resistant rates increased from $57.2 \%$ to $72.7 \%$ in $1996-2001$ and were higher than the report $(66.7 \%)$ by the National Center for STD Control. ${ }^{3}$ The resistant trend was statistically significant $(\mathrm{U}=4.39, \mathrm{p}$ $<0.01$ ). The $\mathrm{MIC}_{50}, \mathrm{MIC}_{90}$ and MICmean in 2001 were 2, 8, and 3.5 times higher than those in 1996, respectively. A high

Table 2 Comparison of susceptibility and PPNG of N gonorrhoeae isolated in Guangzhou during 1996-2001

\begin{tabular}{|c|c|c|c|c|c|c|c|c|c|c|c|c|c|}
\hline \multirow[b]{2}{*}{ Year } & \multirow[b]{2}{*}{ No } & \multicolumn{3}{|l|}{ Penicillin } & \multicolumn{3}{|c|}{ Spectinomycin } & \multicolumn{3}{|c|}{ Ceftriaxone } & \multicolumn{2}{|c|}{ Ciprofloxacin } & \multirow[b]{2}{*}{ PPNG (\%) } \\
\hline & & $\mathbf{S}(\%)$ & I (\%) & R (\%) & $\mathrm{S}(\%)$ & R (\%) & S (\%) & I (\%) & R (\%) & $\mathrm{S}(\%)$ & I (\%) & $\mathbf{R}(\%)$ & \\
\hline 1996 & $201^{*}$ & $=17(8.4)$ & 69 (34.3) & 115 (57.2) & $199(99)$ & $2(1)$ & $120(62.5)$ & $72(37.5)$ & $0(0)$ & $37(18.6)$ & $127(63.8)$ & $35(17.6)$ & $4(2)$ \\
\hline 1997 & 51 & $2(3.9)$ & $13(25.5)$ & $36(70.6)$ & $51(100)$ & $0(0)$ & $40(78.4)$ & $11(21.6)$ & $0(0)$ & $2(3.9)$ & $18(35.3)$ & $31(60.8)$ & $1(2)$ \\
\hline 1998 & 203 & $1(0.5)$ & $81(39.9)$ & $121(59.6)$ & $203(100)$ & $0(0)$ & $122(60.1)$ & $81(39.9)$ & $0(0)$ & $16(7.9)$ & $64(31.5)$ & $123(60.6)$ & 7 (3.4) \\
\hline 1999 & 167 & $3(1.6)$ & $24(14.4)$ & $140(83.8)$ & $167(100)$ & $0(0)$ & $153(91.6)$ & $14(8.4)$ & $0(0)$ & $5(3.0)$ & 31 (18.6) & $131(78.4)$ & $9(5.4)$ \\
\hline 2000 & 61 & $0(0)$ & $17(27.9)$ & $44(72.1)$ & $61(100)$ & $0(0)$ & $50(81.9)$ & $11(18.0)$ & $0(0)$ & $0(0) 15(24.6)$ & $46(75.4)$ & $10(16.4)$ & \\
\hline 2001 & 110 & $1(0.9)$ & $19(17.3)$ & $90(81.8)$ & $110(100)$ & $0(0)$ & $90(81.8)$ & 20 (18.2) & $0(0)$ & $2(1.8)$ & $28(25.5)$ & $80(72.7)$ & $24(21.8)$ \\
\hline
\end{tabular}

*192 strains were tested for ceftriaxone and 199 for ciprofloxacin. 


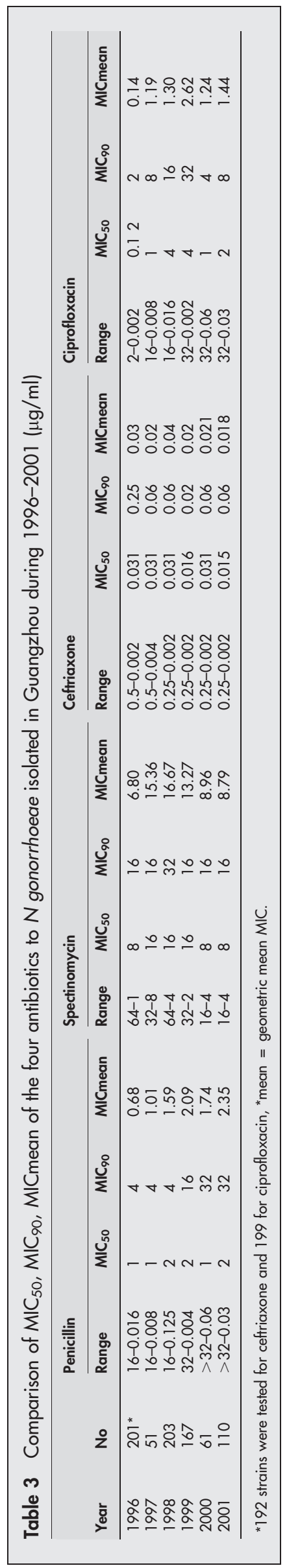

rate $(21.8 \%)$ of PPNGs in 2001 might cause the MIC increase. The high prevalence of PPNGs may cause an increase of penicillin MIC and, in addition, the widespread use of penicillin for treatment might also have contributed to the findings of a steep increase in syphilis infection in Guangzhou in recent years.

Quinolones had been recommended by the Centers For Disease Control and Prevention (CDC) for treatment of gonorrhoea since $1989 .{ }^{8}$ With widely use of these agents, resistance has sharply increased in many districts of south east Asia and the resistant strains have spread recently. In Hong Kong, quinolone resistant $N$ gonorrhoeae (QRNG) increased from $0.5 \%$ in 1992 to $10.4 \%$ in $1994^{\circ}$ and from $60 \%$ in 1998 to $80 \%$ in $2000 .^{7}$ Other information identified an increasing number of QRNG in Japan. ${ }^{10} \mathrm{~A}$ report from Sydney, Australia, represented 3\% QRNG from 1991 to 1994, and in the first 6 months of 1995, the proportion $(8 \%)$ of QRNG rose substantially. ${ }^{11}$ It was considered that the appearance of QRNG in Sydney has been caused by the continuing importation of resistant strains by travellers entering or returning to Australia from Asian destinations. In Guangzhou, our finding was similar. There had been a significant increase in the rate of ciprofloxacin resistant $N$ gonorrhoeae from $17.6 \%$ in 1996 to $72.7 \%(\mathrm{U}=9.67, \mathrm{p}<0.01)$ in 2001. A WHO document stated that an agent should be withdrawn from treatment regimens if the rate of $5 \%$ resistance to the agent occurs. ${ }^{12}$ The $\mathrm{MIC}_{50}, \mathrm{MIC}_{90}$, and MICmean multiplied by 33,16 , and 18.7 times in 1996-9, respectively, and then declined slightly in 2000-1. A recent study on the correlation between the in vitro susceptibility to ciprofloxacin and treatment outcome showed that $96 \%$ isolates from patients who had treatment failure were MICs $1-32 \mu \mathrm{g} / \mathrm{ml} .{ }^{13}$ The emergence and wide spread of the highly ciprofloxacin resistant strains ( $\mathrm{MIC} \geqslant 32 \mu \mathrm{g} / \mathrm{ml}$ ) might mean no dose of this agent (or other quinolones) would effect a cure.

Spectinomycin and ceftriaxone are highly effective as single dose treatment for gonorrhoea. Susceptibility to ceftriaxone was proved to have risen slightly in recent years. ${ }^{14}$ In Guangzhou, the susceptibilities to both of the antibiotics remained unchanged from 1996 to 2001. The MIC $_{50}$, MIC $_{90}$, and MICmean all fell in the sensitive range of the interpretative criteria although two spectinomycin resistant strains were isolated in 1996. The results showed that spectinomycin and ceftriaxone should be the first line treatment for gonorrhoea in Guangzhou, China.

In summary, the results of this study clearly demonstrate that penicillin/ciprofloxacin resistant gonococcal strains are frequently found in Guangzhou. Local susceptibility data of periodic surveillance are useful in guiding clinicians in the use of appropriate antibiotics for the treatment of gonorrhoea.

\section{Authors' affiliations}

W L Cao, Guangzhou Center for STD Control and Prevention, Guangzhou, P R China

H P Zheng, X Z Wu, L G Yang, Guangdong Provincial Centers for Skin Diseases and STIs Control and Prevention, Guangzhou, P R China

\section{REFERENCES}

1 Zhang J. The past, today and future of STDs in China. Chinese J Epidemiol 1998; 19:118-21.

2 Zheng D, Chen Y, Diao J, et al. Analysis on STD epidemiological characteristics of Guangdong province. South China J Dermato-venereol 2002;2:51-4.

3 Ye S. Survey on antibiotic sensitivity of Neisseria gonorrhoeae strains isolated in China. Sex Transm Dis 1994:21:237-9.

4 Cao W, Fei S, Zou G, et al. Analysis of antibiotic susceptibility of Neisseria gonorrhoeae in Guangzhou. J Clin Dermatol 1999;28:223-4.

5 WHO Western Pacific Region Gonococcal Surveillance Programme.

Surveillance of antibiotic susceptibility of Neisseria gonorrhoeae in the WHO Western Pacific Region 1992-4. Genitourin Med 1997;73:355-61. 
6 Van Dyck E, Piot P, Meheus A. Bench-level laboratory manual for sexually transmitted diseases, VDT/89.443. Geneva: World Health Organization, 1989.

7 The WHO Western Pacific Gonococcal Antimicrobial Surveillance

Programme. Commun Dis Intell 2001;25:274-7.

8 Centers for Disease Control. Sexually transmitted diseases treatment guidelines. MMWR 1989;38(s-8):9-24.

9 Kam K, Wong P, Cheung M, et al. Quinolone-resistant Neisseria gonorrhoeae in Hong Kong. Sex Transm Dis 1996;23:102-8.

10 Deguchi T, Yasuda M, Asano $M$, et al. DNA gyrase mutations in quinoloneresistant clinical isolates of Neisseria gonorrhoeae. Antimcrob Agents Chemother 1995;39:561-3.
11 Tapsall JW, Philips EA, Shultz TR, et al. Quinolone-resistant Neisseria gonorrhoeae isolated in Sydney, Australia, 1991 to 1995. Sex Transm Dis 1996;23:425-7.

12 World Health Organization. Guidelines for the management of sexually transmitted infections, WHO/HIV-AIDS/(2001).01; WHO/RPR/01.10:pp 15. Geneva: WHO, 2001:1-5

13 Rahman M, Alam A, Nessa K, et al. Treatment failure with the use of ciprofloxacin for gonorrhea correlates with the prevalence of fluoroquinoloneresistant Neisseria gonorrhoeae strains in Bangladesh. Clin Infect Dis 2001;32:844-9.

14 Ye S, Su X. Sensitivity test of Neisseria gonorrhoeae strains to ceftriaxone. Chinese J Dermato-venereol 1998;12:268-9.

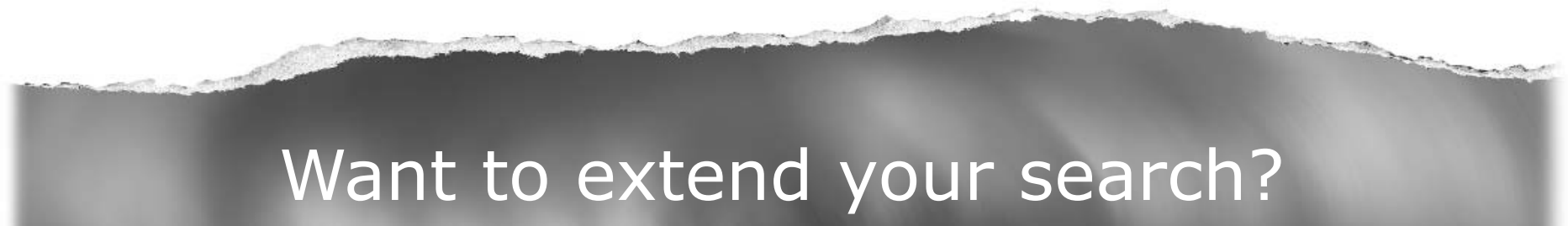

\section{Cross journal searching}

Can't find what you're looking for in Sexually Transmitted Infections? Extend your search across 340+ journals. Search restriction options include specific subject areas (eg. clinical medicine, basic research),

select specific journals or search all available titles.

www.stijournal.com 
PostScript

\section{LETTERS}

Perceived transmissibility of STIs: lack of differentiation between HIV and chlamydia

Sexually transmitted infections (STIs), such as HIV and chlamydia, differ widely in their transmissibility. The estimated probability of HIV transmission from an infected heterosexual man to a woman in one act of unprotected vaginal intercourse is $0.1 \%$, whereas the same probability for chlamydia is $35 \% .^{2}$ This research examines college students' knowledge about the per act transmission probabilities for HIV and chlamydia.

Previous studies reported median perceived transmission probabilities of $50 \%$ and $33.4 \%^{4}$ for HIV for one act of unprotected receptive vaginal intercourse with an infected man. These findings were interpreted as demonstrating "badly overestimated per act transmission probabilities" (Pinkerton et $a l^{4} \mathrm{p} 19$ ). However, the distributions of the estimates were not provided. If estimates are widely dispersed across the entire probability range from $0 \%$ to $100 \%$, interpretations of averages are meaningless and interpreting the data as indicating a systematic overestimation of the transmission probability would be unfounded. We studied this possibility in a sample of college students.

In all, 234 undergraduate university students ( 145 women, 85 men, mean age 21.14 and sex) enrolled in a variety of academic programmes were randomly selected and individually approached after classes. Aside from their age and sex, participants were asked in two separate questions: "What do you think is the probability, in percentages, of a woman becoming infected with HIV (chlamydia) from one unprotected act of vaginal intercourse with an infected man?" The order in which people were asked the two questions was counterbalanced.

Figure 1 presents the distribution of the quite equally dispersed across the entire range from $0 \%$ to $100 \%$, and that distributions do not differ between the two infections (Kolmogorov-Smirnov $\mathrm{Z}=-0.73, \mathrm{p}=0.46$ ) years, SD 2.82, four did not report their age estimates, showing that they are widely and

No age or sex differences were found. Only $3.9 \%$ and $5.6 \%$ of the estimates for HIV and chlamydia, respectively, come close to the correct probabilities if "correct" is defined as smaller than $0.5 \%$ for HIV and between $30 \%$ and $40 \%$ for chlamydia. In all, $34.8 \%$ of the participants falsely estimate that chlamydia has a lower transmission probability than HIV, $39.5 \%$ correctly estimate that chlamydia has a higher transmission probability than HIV, and $25.8 \%$ provide exactly the same percentage estimate for both STIs.

The data show that a large majority of college students clearly lacks knowledge of the transmission probabilities of HIV and chlamydia and does not know that chlamydia is more infectious than HIV. Previous reports of statistical averages of the perceived transmissibility ${ }^{3}$ and their interpretation as indicating a systematic overestimation bias may be unfounded. The results highlight the importance of inspecting response distributions and restraining from reporting statistical averages when distributions are widely dispersed. Furthermore, they highlight that information about transmission probabilities should be incorporated into sexual health programmes in order to make people more aware of STIs that are considerably easier to contract than HIV.

\section{Acknowledgements}

The reported research was funded by a grant from the Social Science and Humanities Research Council of Canada (SSHRC, 410-2002-09) and a New Opportunities Fund from the Canadian Foundation for Innovation (CFI, 4015) to Bärbel Knäuper. We thank Surkhraj Cheema for her help with the data collection, as well as Irv Binik and Sandi Byers for helpful comments on an earlier version of the manuscript.

\section{Contributors}

The study was jointly conceptualised and designed by BK and RK; data were collected by RK, with the assistance of Surkhraj Cheema; BK analysed the data and led the writing; both authors jointly interpreted the findings, reviewed drafts of the manuscript, and approved the final version.

B Knäuper, R Kornik McGill University, Montreal, Canada

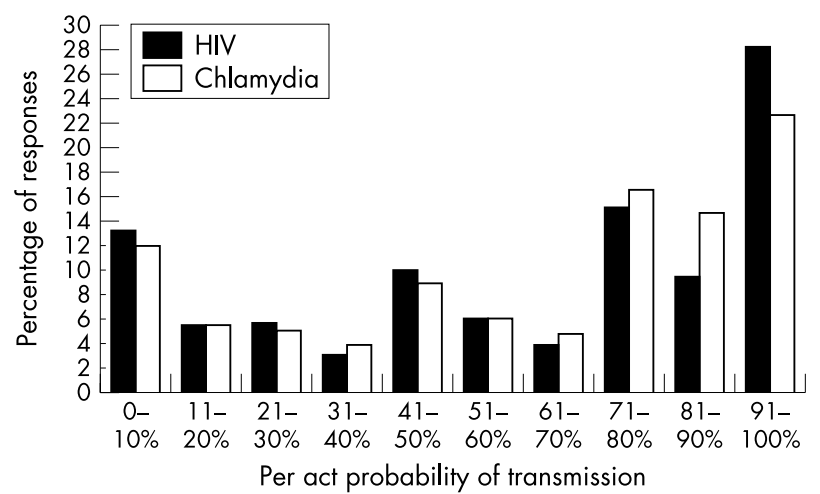

Figure 1 Distribution of estimates for HIV and chlamydia for one act of unprotected vaginal intercourse with an infected man.
Correspondence to: Bärbel Knäuper, Department of Psychology, McGill University, 1205 Dr Penfield Avenue, Montreal, QC, Canada, H3A 1B1. barbel.knauper@mcgill.ca

Accepted for publication 12 August 2003

\section{References}

1 Mastro TD, de Vincenzi I. Probabilities of sexual HIV-1 transmission. AIDS 1996; 10(Suppl A):S75-82.

2 Katz BP, Caine, Jones RB. Estimation of transmission probabilities for chlamydial infection. In: International symposium on human chlamydial infections. Chlamydial infections proceeds of the seventh international symposium on human chlamydial infections. New York: Cambridge University Press, 1990:567-70

3 Linville PW, Fischer GW, et al. AIDS risk perceptions and decision biases. In: Pryor JB, Reeder GD, eds. The social psychology of HIV infection. Hillsdale, NJ: Erlbaum, 1993:5-38.

4 Pinkerton SD, Wagner-Raphael LI, Craun CA, et al. A quantitative study of the accuracy of college students' HIV risk estimates. J Appl BioBehav Res 2000;5:1-25.

\section{A new method for extended trichomonad storage}

With the introduction of the InPouch test for Trichomonas vaginalis, ${ }^{1} T$ gallinae, and $T$ foetus, it was desirable to have a procedure available for maintaining extended culture viability. The three trichomonads are viable after 8 days by subculture in the InPouch at $33^{\circ} \mathrm{C}$. Extended viable storage of these three trichomonads is the subject of this letter.

We have evaluated various procedures involving freezing 24 hour InPouch cultures at $-70^{\circ} \mathrm{C}$. We now report a procedure that has demonstrated storage of viable trichomonad cultures for more than 2 years.

The freshly subcultured trichomonads are incubated at $35^{\circ} \mathrm{C}$ for 24 hours, which should produce a viable count of approximately $1.0 \times 10^{5} / \mathrm{ml}$. It is important to note that subsequent subculture will require an adequate nutrient available for growth in the pouch. Then $0.1 \mathrm{ml}$ of pure sterile glycerol is added to the medium in the pouch and thoroughly mixed employing the "shoeshine" technique. It is important to immediately place the pouch in a $-70^{\circ} \mathrm{C}$ freezer.

After freezing most of the trichomonads in the pouch are non-viable, but successful subculture is routinely achieved upon thawing. When the pouch is removed from the freezer, it should be immediately placed in an incubator at $35-37^{\circ} \mathrm{C}$. After 3 days a few viable trichomonads will be observed, and after 4 days it may be subcultured.

This procedure has been effective for $T$ vaginalis, $T$ gallinae, and $T$ foetus.

K A Borchardt CBLS, San Francisco State University, San Francisco, CA, USA

$J$ H Hall

BioMed Diagnostics, Inc, San Jose, CA, USA 
Correspondence to: K A Borchardt, CBLS, San Francisco State University, San Francisco, CA, USA info@biomedl.com

Accepted for publication 19 June 2003

\section{Reference}

1 Borchardt KA, Hernandez V, Miller S, et al. A clinical evaluation of trichomoniasis in San Jose, Costa Rica using the InPouch TV test. Genitourin Med 1992;68:328-30.

\section{"Water can" penis caused by tuberculosis}

Tuberculosis of the penis is a very rare condition, clinically manifesting as primary or secondary tuberculosis or tuberculide. ${ }^{1}$ Penile involvement secondary to urethral tuberculosis is rare and its presentation with periurethral fistulas leading to "water can" penis is unknown. We report this rather intriguing condition in a patient.

A 40 year old male agricultural labourer presented with a l year history of purulent discharge per urethra with multiple discharging sinuses on the tip of the penis. The patient was asymptomatic about a year ago, when he developed multiple nodules on the glans penis that ulcerated to discharge purulent material. These nodules became persistent sinuses and discharged pus. Within a few weeks, he started passing urine through these sinuses in the glans penis. He also experienced difficulty in micturition but it was not associated with pain or strangury. The patient had no systemic complaints. He was married with two children and had no history of extramarital contact or genital ulcers.

On physical examination, the penis shape was like a saxophone. The prepuce and glans penis were oedematous and indurated. The glans penis had multiple sinuses around the urethral meatus (fig 1). On squeezing the penis, pus was expressed from the meatus and the sinuses. The glans penis also showed areas of depigmentation (vitiligo). The distal part of the shaft of the penis showed induration involving corpora cavernosa whereas the proximal part was devoid of any lesion. The testes, bilateral epididymis, and scrotum were normal. The vas deferens was normal on

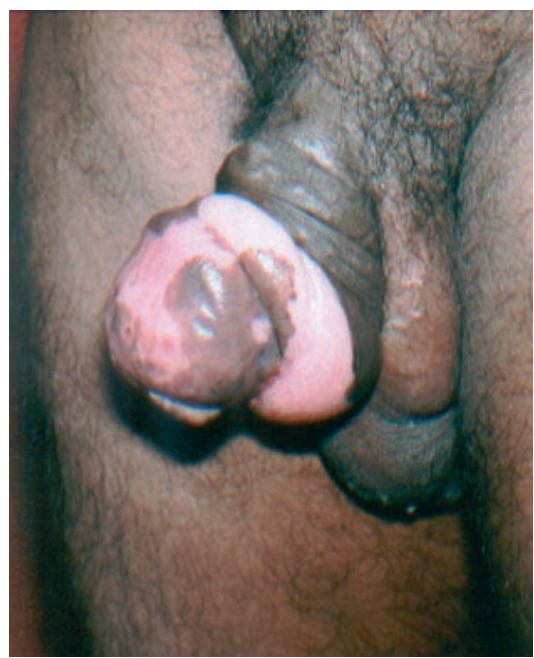

Figure 1 Saxophone penis with multiple sinus openings over the glans penis.

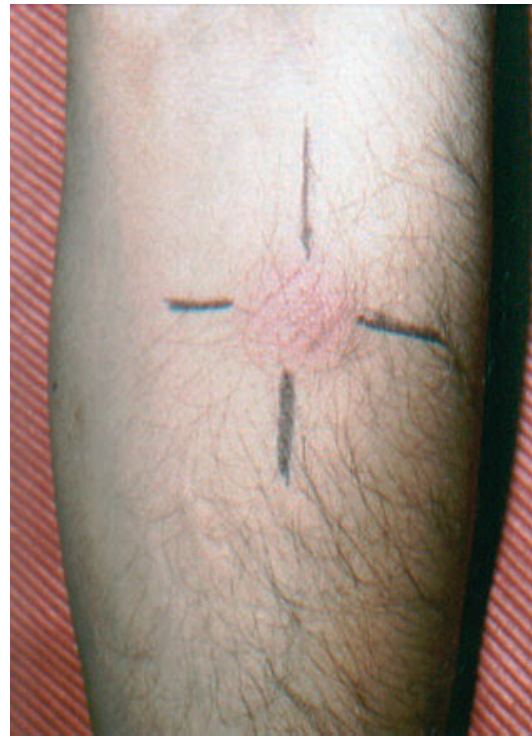

Figure 2 Forearm showing positive Mantoux reaction.

palpation. The prostate was normal on rectal examination.

The routine haemogram revealed an elevated erythrocyte sedimentation rate of $100 \mathrm{~mm}$ in the first hour. His liver and renal functions were normal. The discharge smear stained with Gram stain and Zeihl-Neelsen stain. The Gram stained smear revealed numerous pus cells and acid fast stain showed abundant acid fast bacilli. Culture for Mycobacterium tuberculosus grew contaminants. A roentgenogram of the chest and penis was unremarkable. An intravenous pyelogram was normal. Voiding cystourethrography revealed glandular urethral stricture with urethrocutaneous fistulas. Ultrasonography of abdomen and prostate was normal. Mantoux skin test was strongly positive $(30 \times 30 \mathrm{~mm})$ (fig 2$)$. His venereal disease research laboratory test (VDRL) and HIV serology was non-reactive.

Based on these clinical features, positive Mantoux test and acid fast bacilli in the urethral smear, the diagnosis of urethral tuberculosis with urethrocutaneous fistula was made. The patient was started on antituberculous treatment comprising isoniazid $300 \mathrm{mg}$, rifampicin $600 \mathrm{mg}$, pyrazinamide $1500 \mathrm{mg}$, and ethambutol $800 \mathrm{mg}$ per day. The patient showed marked improvement after 4 weeks of treatment. The sinuses closed and discharge ceased. Patient was referred to urology for management of stricture, which was planned after the antituberculous treatment. The patient tolerated antituberculous treatment and completed 9 months of treatment with remarkable recovery in the swelling of the penis.

Genital involvement occurs in $50 \%$ of male patients with urogenital tuberculosis. Penile tuberculosis is rare with less than $1 \%$ of patients having penile involvement. ${ }^{2}$ Tuberculosis of the penis usually presents as ulcers, tubercular cavernositis, or nodules. In most cases, the lesion appears as a superficial, solitary, painless ulcer on the glans penis. It can be clinically indistinguishable from malignant disease. ${ }^{3}$ Rarely, lesions may persist as solid nodule or cavernositis with ulceration. ${ }^{45}$ Papulonecrotic tuberculide may also present as an ulcer on the penis. ${ }^{1}$ Penile involvement may occur secondary to coexisting urinary tract tuberculosis. The transmission occurs secondary to bacilluria in these patients. Infection of the penis may occur by direct contact at the time of intercourse with a partner having urogenital tuberculosis. ${ }^{2}$

Tuberculosis of male urethra is an uncommon condition and presents as urethral strictures, periurethral abscesses, or fistula formation. Fistulas can occur in the perineum leading on to "water can" perineum. ${ }^{6}$ Similar occurrence of fistulas in penis can aptly be designated as "water can" penis. In our case, penile involvement occurred secondary to urethral tuberculosis. Such involvement of the penis by tuberculosis is unique and not reported in the literature. "Water can perineum" is also known to occur with gonorrhoea but our patient had a negative urethral smear for Gram negative diplococci and had features suggestive of urethral tuberculosis. Further, the strictures, fistulas, and lymphoedema had led to "saxophone" deformity of the penis. Such deformity is well known with lymphogranuloma venereum, but is unknown in tuberculosis.

K Karthikeyan, D M Thappa, K N Shivaswamy Dermatology and STD Department, JIPMER Pondicherry - 605006, India

Correspondence to: Professor D M Thappa, Dermatology and STD Department, JIPMER Pondicherry - 605006, India; dmthappa@jipmer.edu

Accepted for publication 4 September 2003

\section{References}

1 Vijaikumar M, Thappa DM, Kaviarasan PK. Papulonecrotic tuberculid of the glans penis (correspondence). Sex Transm Infect 2001; 77:147.

2 Elkin M. Urogenital tuberculosis. In: Pollack HM, eds. Clinical urography: an atlas and textbook of urological imaging. Philadelphia: WB Saunders, 1990:1030-52

3 Gow JG. Genitourinary tuberculosis. In: Walsh PC, Ritik AB, Stamey TA, et al, eds. Campbell's urology, Vol 1. 6th ed. Philadelphia: WB Saunders, 1992:951-81.

4 Venkataramaiah NR, van Raalte JA, Dutta SN Tuberculous ulcer of penis. Postgrad Med J 1982;58:59-60.

5 Ramesh V, Vasanthi R. Tuberculous cavernositis of the penis. Genitourin Med 1989;65:58-9.

6 Symes JM, Blandy JP. Tuberculosis of male urethra. Br J Urol 1973;45:432-6.

South Asians with HIV in London: is it time to rethink sexual health service delivery to meet the needs of heterosexual ethnic minorities?

Recent conservative estimates suggest that at the end of 2002, 4.8 million people were living with HIV/AIDS in south Asia including 4.58 million in India. ${ }^{1}$ In the United Kingdom there are estimated to be 1.5 million people of south Asian ethnicity. While the National Strategy for Sexual Health aims to improve health care in those who have HIV through earlier diagnosis, ${ }^{2}$ studies have shown that that other ethnic minority groups present with advanced disease and not through routine genitourinary medicine (GUM) screening. ${ }^{3}$ We studied the case notes of all adults self defining as of Indian, Pakistani, Bangladeshi, or Sri Lankan ethnicity diagnosed HIV positive from 
Table 1 Characteristics of presentation of study population at time of HIV diagnosis $(n=117)$

\begin{tabular}{|c|c|c|c|c|}
\hline & $\begin{array}{l}\text { Heterosexual } \\
\text { men }(n=45)\end{array}$ & $\begin{array}{l}\text { Homosexual } \\
\text { men }(n=36)\end{array}$ & $\begin{array}{l}\text { Heterosexual } \\
\text { women }(n=27)\end{array}$ & $\begin{array}{l}\text { Other risk } \\
\text { groups }(n=9)\end{array}$ \\
\hline $\begin{array}{l}\text { AIDS illness at } \\
\text { presentation }\end{array}$ & $16(36 \%)$ & $6(16 \%)$ & $2(7 \%)$ & $1(11 \%)$ \\
\hline $\begin{array}{l}\text { Median CD4 cell count } \\
\times 10^{6} / \text { ( } \text { (range) }\end{array}$ & $178(3-1,023)$ & $381(4-810)$ & $377(10-1,104)$ & $151(50-795)$ \\
\hline $\begin{array}{l}\text { Median HIV viral load } \\
\text { copies/ml (range) } \\
\text { Reasons for HIV test }\end{array}$ & $\begin{array}{l}24500(50- \\
1000000)\end{array}$ & $\begin{array}{l}24636(425- \\
3000000)\end{array}$ & $\begin{array}{l}7822(173- \\
489184)\end{array}$ & $\begin{array}{l}12870(6676- \\
57530)\end{array}$ \\
\hline AIDS/symptomatic & $27(60 \%)$ & $11(31 \%)$ & $7(26 \%)$ & $2(22 \%)$ \\
\hline $\begin{array}{l}\text { Known HIV+ sexual } \\
\text { partner }\end{array}$ & $3(7 \%)$ & $4(11 \%)$ & $12(44 \%)$ & 0 \\
\hline $\begin{array}{l}\text { Routine screen for } \\
\text { sexually transmitted } \\
\text { infections }\end{array}$ & $1(2 \%)$ & $16(44 \%)$ & $1(4 \%)$ & 0 \\
\hline Patient request & $7(15 \%)$ & $3(8 \%)$ & $2(8 \%)$ & $2(22 \%)$ \\
\hline Child positive & $3(7 \%)$ & 0 & $3(11 \%)$ & 0 \\
\hline Insurance/visa purposes & $3(7 \%)$ & $1(3 \%)$ & 0 & $2(22 \%)$ \\
\hline Antenatal screening & 0 & 0 & $2(7 \%)$ & 0 \\
\hline Other & $1(2 \%)$ & $1(3 \%)$ & 0 & $3(34 \%)$ \\
\hline
\end{tabular}

January 1985 to December 2002 attending four HIV treatment centres in London. Information was collected on demography, mode of first presentation, and clinical stage of HIV infection.

In all, 117 patients were identified, 30 women and 87 men. The number of new diagnoses among south Asians increased by more than threefold over the period 1996 to 2002 compared to earlier years (25 diagnoses before 1996, 90 diagnosed from 1996-2002).

The median age at diagnosis was 38 years (range 19-64 years) for men and 28 years (range 20-55 years) for women. Forty five patients $(38 \%)$ had originated from Africa, $28(24 \%)$ from India, and 18 (15\%) from the United Kingdom. The majority were of Indian ethnicity $(95 / 117 ; 81 \%)$ with the next largest ethnic group being Sri Lankan (12) $117 ; 10 \%$ ).

The primary mode of transmission was heterosexual sex $(72 / 117 ; 62 \%)$ with transmission through sex between men accounting for a further $31 \%(36 / 117)$ of cases. Four infections were acquired through blood transfusion, two through injecting drug use, one from a needle stick injury, and in two cases risk behaviour could not be identified. The majority $(39 \%, 45 / 117)$ of patients identified Africa as the probable place of infection with $28 \%$ and $15 \%$ probably infected in the United Kingdom and India, respectively.

There were substantial differences in the reasons for testing between individuals in the main risk groups. In particular, heterosexual men and women were both significantly less likely than homosexual men to be diagnosed via routine attendance at a GUM clinic ( $2 \%$ and $4 \%$, compared to $44 \%$, respectively, $\mathrm{p}=<0.001$, Fisher's exact test). Among heterosexuals, the main reason for testing in men was symptomatic HIV infection/AIDS ( $60 \%$ of men but only $26 \%$ of women), whereas women were more likely to be tested through partner notification of a known HIV+ sexual contact ( $44 \%$ v $7 \%$ in males) (table 1).

The median CD4 count at presentation overall was 300 (range $3-1104$ ) cells $\times 10^{6} / 1$. However, male heterosexuals presented with significantly lower CD4 counts (median 178, range $3-1023$ cells $\times 10^{6} / 1$ ) than either homosexual men (median 381, range 4-810 cells $\times 10^{6} / \mathrm{l} ; \mathrm{p}=0.01$ ) or heterosexual women (median 377, range 10-1104; $\mathrm{p}=0.02$ ).

While there are methodological limitations with retrospective case note reviews and differing reporting categories used for Asian ethnicity, our data confirm national surveillance reports of increasing HIV infection among Britain's south Asian communities. The four centres taking part in this study reported 90 cases from 1996-2002 representing one in three of all HIV positive south Asians reported in this time period. Despite the fact that the majority of these were not diagnosed through routine GUM screening the median CD4 count at presentation of heterosexual and homosexual men was consistent with national trends. ${ }^{6}$ Indeed, south Asian women presented higher CD4 counts than seen nationally, primarily attributable to effective partner notification. While south Asians still represent less than 5\% of all reported HIV positive diagnoses in UK ethnic minority groups ${ }^{5}$ (Asians 334; black Africans 8848; black Caribbeans 844) numbers are likely to continue to increase in the future and methods for encouraging early presentation need to be developed in response to this.

G Sethi, C J Lacey

St Mary's Hospital, London W2 INY, UK

K A Fenton, I G Williams

Department of Sexually Transmitted Diseases, Royal Free and University, College Medical School, London WCIE 6AU, UK
E Fox

St George's Hospital, London SW17 ORE, UK

C A Sabin

Department of Epidemiology and Population Sciences,

Royal Free and University College Medical School,

London, UK

A Shaw, M Kapembwa

Northwick Park Hospital, Harrow HAI 3UJ, UK

Correspondence to: Dr Gulshan Sethi, Jefferiss Wing,

St Mary's Hospital, London W1 2NY, UK; gsethi@ doctors.org.uk

Accepted 30 October 2003

\section{References}

1 UNAIDS. AIDS epidemic update, 2002.

2 Department of Health. National strategy for sexual health and HIV. London: $\mathrm{DoH}, 2001$.

3 Burns FM, Fakoya AO, Copas AJ, et al. Africans in London continue to present with advanced HIV disease in the era of highly active antiretroviral therapy. AIDS 2001;15:2453-5.

4 Del Amo J, Petruckevitch A, Phillips AN, et al. Spectrum of disease in Africans with AIDS in London. AIDS 1996; 10:1563-9.

5 Health Protection Agency, HIV/STI Division Communicable Disease Surveillance Centre and for the Scottish Centre for Infection and Environmental Health. HIV/AIDS Quarterly Surveillance Tables Cumulative UK data. CDSC, June 2003.

6 Health Protection Agency, HIV/STI Division Communicable Disease Surveillance Centre. HIV/AIDS in the UK an epidemiological review. London, 2000.

\section{Failure to maintain patient access to GUM clinics}

We read with interest the article published by Cassell et al ${ }^{1}$ about the maintenance of patient access to genitourinary medicine (GUM) clinics following a switch to an appointment based system. Their data show no significant change in the age, ethnic mix, symptom status, and disease mix following the change to appointments. In addition, such a system of $35 \%$ prebooked appointments produced an increase in the number of patients seen over that time.

A new appointment based system was introduced at the John Hunter genitourinary medicine clinic at the Chelsea and Westminster Hospital in October 2001. This comprised $80 \%$ of appointments which were prebooked with a further $20 \%$ allocated on the day following triage by a nurse. All patients with symptoms were seen on the day of presentation.

We have analysed the results from two 9 month periods, taken immediately before the change and 3 months after the introduction of an appointment based system. The total number of patients and sex ratio seen

Table 1 Total number of STI diagnoses

\begin{tabular}{llll}
\hline & No (\%) & $\begin{array}{l}\text { Relative drop (\%) } \\
\text { (95\% Cl) }\end{array}$ \\
\cline { 2 - 4 } & Jan-Sept 2001 & Jan-Sept 2002 & 3.2 (2.8 to 3.5) \\
\hline $\begin{array}{l}\text { Total no of } \\
\text { patients } \\
\text { attending }\end{array}$ & 11714 & 11345 & \\
$\begin{array}{l}\text { Patients new } \\
\text { to clinic }\end{array}$ & $5191(44.3)$ & 4669 (41.2) & \\
\hline
\end{tabular}


Table 2 Details of STls diagnosed in men and women

\begin{tabular}{|c|c|c|c|c|c|c|}
\hline & \multicolumn{2}{|l|}{ Male } & \multirow[b]{3}{*}{ p Value using $\chi^{2}$ test } & \multicolumn{2}{|l|}{ Female } & \multirow[b]{3}{*}{$p$ Value using $\chi^{2}$ test } \\
\hline & $\begin{array}{l}\text { Jan-Sept } 2001 \\
(\mathrm{n}=6920)\end{array}$ & $\begin{array}{l}\text { Jan-Sept } 2002 \\
(n=6659)\end{array}$ & & $\begin{array}{l}\text { Jan-Sept } 2001 \\
(n=4794)\end{array}$ & $\begin{array}{l}\text { Jan-Sept } 2002 \\
(n=4690)\end{array}$ & \\
\hline & \multicolumn{2}{|c|}{ No (prevalence per 100 patient) } & & \multicolumn{2}{|c|}{ No (prevalence per 100 patient) } & \\
\hline $\mathrm{Al}$ & $37(0.5)$ & $53(0.8)$ & 0.061 & $0(0.0)$ & $3(0.1)$ & $0.121^{*}$ \\
\hline Bl & $262(3.8)$ & $190(2.9)$ & 0.002 & $41(0.9)$ & $35(0.7)$ & 0.552 \\
\hline $\mathrm{C} 4 \mathrm{a} / \mathrm{C} 4 \mathrm{c}$ & $244(3.5)$ & $179(2.7)$ & 0.005 & $187(3.9)$ & $199(4.2)$ & 0.399 \\
\hline $\mathrm{C} 4 \mathrm{~h}$ & $683(9.9)$ & $479(7.2)$ & $<0.001$ & - & - & - \\
\hline $\mathrm{ClOa}$ & $89(1.3)$ & $55(0.8)$ & 0.009 & $111(2.3)$ & $80(1.7)$ & 0.035 \\
\hline $\mathrm{Clla}$ & $264(3.8)$ & $254(3.8)$ & 0.998 & $147(3.1)$ & $164(3.5)$ & 0.239 \\
\hline $\begin{array}{l}\text { Total diagnosed with an } \\
\text { STI at this episode }\end{array}$ & $1579(22.8)$ & $1210(18.2)$ & $<0.001$ & $486(10.1)$ & $481(10.3)$ & 0.849 \\
\hline
\end{tabular}

*p Value using $\chi^{2}$ test with Yates's correction.

(A1) Primary diagnosis of syphilis; (B1) gonorrhoea; (C4a, C4c) uncomplicated chlamydia; (C4h) non-gonococcal urethritis; (C10a) first attack of genital herpes; (C1 la) anogenital warts.

over this period did not change. We have shown however a dramatic change in the number of STI diagnoses made over these two periods.

Tables 1 and 2 highlight a significant fall in the total number of STI diagnoses for gonorrhoea (B1), uncomplicated chlamydia (C4a, $\mathrm{C} 4 \mathrm{c})$, non-gonococcal urethritis $(\mathrm{C} 4 \mathrm{~h})$, and first attack of genital herpes (C10a) in our male patients. The only significant fall for women was seen in the diagnosis of a first attack of genital herpes. There was no significant change for both sexes in the diagnosis of anogenital warts (Clla) between the two systems. The rise in primary diagnosis of syphilis $(\mathrm{Al})$ reflects the beginning of the current epidemic in London, boosted further by a proactive approach to diagnosis in our HIV positive population.

This fall in acute STI diagnoses in men was approximately twice as marked for men who have sex with men (data not shown).

Our aim in planning the change to a primarily appointment based system was to improve patient experience, by reducing waiting times, and enhance access for symptomatic patients into reserved appointment slots. These data show evidence for an opposite effect which we believe has resulted from asymptomatic individuals requiring sexual health screening booking the majority of clinic appointments well ahead of their appointment, thereby reducing access at convenient times for symptomatic individuals who telephone.

To respond to this we have adjusted the ratio of prebooked versus emergency appointments and significantly amended our approach to triage of symptomatic patients, in an attempt to reverse these trends Particular attention is now being given to our telephone booking protocol to facilitate symptomatic patients to achieve prompt, immediate appointments. We are publishing these findings to inform others who are implementing changes in clinic appointment schedules, designed to enhance access, to better tailor the booking and triage systems to achieve this goal. We will continue to audit our system to examine the effect of the revised system and to further examine why the change to our appointment system disproportionately affected those men who have sex with men.

A S Menon-Johansson, D A Hawkins, S Mandalia, S E Barton, F C Boag Chelsea and Westminster Healthcare NHS Trust, London, UK
Correspondence to: Dr A S Menon-Johansson, Chelsea and Westminster Healthcare NHS Trust, London, UK; anatole.menon-johansson@chelwest.

Accepted for publication 23 June 2003

\section{References}

1 Cassell JA, Brook MG, Mercer $\mathrm{CH}$, et al. Maintaining patient access to GUM clinics: is it compatible with appointments? Sex Transm Infect 2003:79:11-15

2 Winston A, Hawkins DA, Mandalia S, et al. Is increased surveillance for asymptomatic syphilis in an HIV outpatient department worthwhile? Sex Transm Infect 2003;79:257-9.

\section{Prevalence of HSV-1/HSV-2 antibodies in HIV seropositive patients in Coventry, United Kingdom}

The seroprevalence of herpes simplex virus (HSV) antibody among HIV patients within the United Kingdom is unknown. We therefore conducted a HSV seroprevalence study in HIV patients attending our genitourinary medicine clinic from January 2000 to December 2001. Our previous study ${ }^{1}$ revealed an overall prevalence of HSV-1 (60\%), HSV-2 $(20 \%)$, and both HSV-1 and HSV-2 $(12 \%)$ among male and female genitourinary medicine clinic attendees who were either HIV negative or whose HIV status was unknown.

Serum samples from 96 consecutive ethnically diverse HIV patients were collected during routine investigations, and tested for HSV type specific antibodies by monoclonal antibody blocking enzyme linked immunoassay. ${ }^{2}$ Out of 96 patients, two HSV- 1 and three HSV-2 antibody test results were equivocal in four individuals. These were excluded from the analysis and results are presented here for 92 patients

There were 56 men and 36 women in the study: $46(50 \%)$ were white, $43(47 \%)$ black African, and three were from other ethnic groups. All the black Africans were heterosexuals and $71 \%$ of men were homosexuals. The median age was 35 years (range $21-80$ ).

HSV-l seroprevalence was $86 \%$ among men and $97 \%$ among women $(p=0.14)$. HSV-2 seroprevalence was $50 \%$ among men whereas it was 94\% among women $(\mathrm{p}=0.0001)$. There was no statistically significant difference between the seroprevalence of HSV-l between white and black people. However, seroprevalence of HSV-2 and both serotypes was significantly higher among black than among white people.

This study shows very high seroprevalence of HSV-1 (90\%), HSV-2 (67\%), and both HSV-1 and HSV-2 (64\%) among our HIV positive cohort in Coventry. The high prevalence of HSV-2 in women is possibly because most of them were black African and acquired HIV through sex. These findings may have important public health implications as the high rate of HSV-2 is therefore likely to act as a cofactor in HIV transmission.

P S Allan, S Das

Department of GU Medicine, Coventry and Warwickshire Hospital, Coventry CV1 4FH, UK srisallen@yahoo.co.uk

Accepted for publication 16 July 2003

\section{References}

1 Narouz N, Allan PS, Wade AAH, et al. Genital herpes serotesting: a study of the epidemiology and patients knowledge and attitude among STD clinic attenders in Coventry, UK. Sex Transm Infect 2003;79:35-41.

2 Van Doornum GJJ, Slomka MJ, Buimer M, et al. Comparison of a monoclonal antibody-blocking enzyme-linked immunoassay and a strip immunoblot assay for identifying type-specific herpes simplex type 2 serological responses. Clini Diagn Lab Immunol 2000;7(4):641-4.

\section{BOOK REVIEW}

Effective Sexual Health Interventions: Issues In Experimental Evaluation

Ed Judith M Stephenson, John Imrie, and Chris Bonell. Pp 232; £55. Oxford: Oxford University Press, 2003. ISBN 0-19-850849-2.

HIV spreads more every day and there are epidemics of other STIs in both the developed and developing world at least in part because the fear of HIV appears to be receding in the population. Our current strategies to contain these problems are meeting with limited success and treatment of people who are already infected, important though that is in controlling bacterial infections, is much less effective with continuing viral infections. There is an urgent need to develop and to test better 
methods of helping people to reduce their risky sexual behaviour.

This book is excellent, brief, fairly comprehensive, and very readable. Its focus is designing studies on the effectiveness of sexual health interventions. If we are to get anywhere in improving behavioural interventions it is essential that what is done is carefully evaluated.

The first three chapters of the book are concerned with methodology, particularly whether randomised controlled (RCTs) trials are an appropriate method for evaluating interventions in this area. While this section of the book is well argued on all sides it doesn't really break any new ground. The strengths and weaknesses of RCTs in behaviour change are pretty much what they are in any other area of medicine. Methodologies don't exist as stand alone phenomena, whether an RCT or some other methodology is appropriate depends simply on what question one is seeking to answer.

The second section of the book covers models of behaviour change and the choice of design and outcome measures. It is clear that one of the main problems in intervening in sexual health is the poor quality of the available psychological models and our real lack of understanding about why people behave as they do. Without understanding why people behave as they do it is difficult to help them to change. It is interesting that models of health behaviour never seem to get discarded, even the ones that are known to be weak. There are particularly strong chapters on cluster randomisation, an approach which probably gives rise to more inappropriate statistics than any other and on complex behavioural measures. The latter should be required reading for anyone measuring any aspect of risky sexual behaviour simply because it highlights how weak many studies of sexual behaviour-and not just of behaviour change-are in this respect.
The book ends by looking at generalisability in its broadest sense. Generalisability is an area that tends to get overlooked. Even a highly successful behaviour change programme would be of no use in developing countries if it was labour intensive and dependent on highly skilled staff for its delivery.

I would recommend this book to anyone planning a trial or simply seeking to understand the existing literature. I would however caution that to make sense of it you will have to look at some of the available reviews of the behaviour change literature since the book assumes some knowledge, or willingness to acquire knowledge, of these.

J Green

St Mary's and Imperial College Hospital, London, UK; mail@john-green.com

\section{NOTICES}

\section{Australasian Sexual Health Conference 2004: Behind the Mask}

This conference will be held at the Adelaide Convention Centre, South Australia, on 31 March to 3 April 2004. For further details please contact Dart Associates (tel +61 29418 9396/97; email dartconv@mpx.com.au; and website http://www.acshp.org.au).

\section{8th European Society of \\ Contraception Congress}

The 8th European Society of Contraception Congress will be held from 23-26 June 2004 in Edinburgh, Scotland, UK. For further details please contact ESC Central Office, c/o Orga-Med Congress Office, Essenestraat 77,
B-1740 Ternat, Belgium (tel: +32 258208 52; fax: +32 258255 15; email: orgamed.ann@ pandora.be; and website: http://www. contraception-esc.com/edinburg.htm).

\section{CORRECTIONS}

In the October issue of STI table 2 of the paper by Zheng et al (Zheng HP, Cao WL, Wu XZ, Yang LG. Antimicrobial susceptibility of Neisseria gonorrhoeae strains isolated in Guangzhou, China, 1996-2001. Sex Transm Infect 2003;79:399-402) was published with incorrect column headings. Under the heading spectinomycin only "S(\%)" and "R(\%)" should appear and under ceftriaxone "S(\%)", "I $(\%)$ ", and "R(\%)" should appear, in that order. Under ciprofloxacin "S(\%)", "I(\%)", and "R(\%)" should appear. A corrected version of the table can be found on the website at http://sti.bmjjournals.com/cgi/ content/full/79/5/399/DCl.

The authors of a letter in the December issue of STI (Dave SS, Johnson AM, Fenton KA, Mercer CH, Erens B, Wellings K. Male circumcision in Britain: findings from a national probability sample survey. Sex Transm Infect 2003;79:499-500) were listed in the wrong order. The correct author list should be as follows: Dave SS, Fenton KA, Mercer $\mathrm{CH}$ Erens B, Wellings K, Johnson AM.

In the corresponding author's address of a letter published in the December issue (Bhatia R, Prabhakar S, Shedde D, et al. Coexistent cranial tuberculomas and tuberculosis of the cervix in a postmenopausal woman. Sex Transm Infect 2003;79:496-7) All India Institute of Medical Sciences was incorrectly printed as AU India Institute of Medical Sciences. 